\title{
Analysis for Mooring System of Ship
}

\author{
Shenghui Tao, Hui Liu
}

\begin{abstract}
The mooring system of a bulk carrier under wave, wind and current action is numerically simulated by creating the finite element models in ANSYS-AWQA. The numerical simulation of the ship mooring system under three typical working conditions is carried out, and the tension of the anchor chain is checked, the motion response is analysed, and the numerical calculation results are analysed. The results show that the analysis for the motion responses of the mooring system and the tension check of the mooring lines play an important role in the construction and safety of the ship. In addition, the numerical simulation analysis can provide the basis and guarantee for the selection of the suitable mooring system, and it has great meaning for reducing the economic loss.
\end{abstract}

Index Terms - mooring system, finite element method, ANSYS-AQWA, mooring forces, motion responses.

\section{INTRODUCTION}

Since the beginning of the 21 st century, with the continuous advancement of economic globalization, trade between countries has become more frequent, and shipping has become the main mode of transportation. However, when the ship is parked or encounters severe sea conditions, it will inevitably be affected by wind, wave and flow loads, resulting in complex multi-degree-of-freedom coupling movements. Therefore, in order to ensure the safe operation of the ship, its mooring system is essential.

Per.I. Johansson [1] established a finite element model of the mooring system in his doctoral thesis in 1976 and analyzed its dynamic response. He not only considers the speed of the mooring system and the sudden change of the tension of the anchor chain, but also considers the displacement of the mooring system from the equilibrium position, and its finite element model is a nonlinear model. Therefore, he solves the time domain of the finite element model, and the data obtained can be used to analyze the anchor chain at a certain moment. Based on the predecessors, Per. I. Johansson creatively proposed a new calculation method to solve the numerical integral of the coupled equation of motion. Subsequently, Jason. I. Gobat and Mark. A. Gro. Senbaug [2] proposed a new empirical model for calculating the dynamic tension caused by the vertical movement of the upper end of the catenary chain. This new empirical model works well for ocean wave frequency forces and can also be used to calculate the standard deviation of the chain tension. Comparing the calculation results of the model with the actual ocean anchor chain results measured under a series of sea conditions, the maximum error between the two is between $8 \%$ and $-11 \%$, and the error of the standard deviation is between $2 \%$ and $3 \%$. between. The study found that when the horizontal motion produces significant changes, the place with the largest

Shenghui Tao, School of Naval Architecture and Ocean Engineering, Jiangsu University of Science and Technology, Zhenjiang 212003, China.

Hui Liu, School of Naval Architecture and Ocean Engineering, Jiangsu University of Science and Technology, Zhenjiang 212003, China. average tension and dynamic tension is most likely to produce the largest error. Based on the previous studies, A. P. Shashinkala [3] used the finite element method to study the three-dimensional problem of wave interference on single-point mooring barges. By comparing the values obtained by the finite element method with the model test data obtained under the irregular wave and regular wave conditions, they obtained the relationship between the response of different mooring barges and the stiffness coefficient of the anchor chain. The analysis results and the experimental data are basically the same whether in the case of regular waves or irregular waves. Bingham [4] uses a three-dimensional method to solve the ship's motion response; Inoue and Islam [5-7] consider the nonlinear effects and analyze the hydrodynamic interaction of the mooring system; Ohkushu [8] uses two-dimensional theory. The interaction between floating bodies is explored; Kordan [9] proposed a theory to simulate the coupling analysis between structures under oblique waves; Choi and Hong [10] used high-order boundary element method to analyze the mutual interaction between two structures. effect. [11] used the frequency domain method to study the force caused by the anchor chain in the low frequency slow damping force caused by wave motion. In essence, the damping caused by the chain is inseparable from the initial phase between its movements. Therefore, the phase information can be obtained by frequency domain analysis, and then the second-order tension response function of the anchor chain can be derived by perturbation theory. Finally, the comparison example and the corresponding time domain result are obtained. The results obtained by the frequency domain method and the time domain method are obtained. The results are basically the same.

According to the actual engineering needs, ANSYS software is used to establish the finite element model of anchorage mooring for $120.1 \mathrm{~m}$ coastal bulk carrier. The numerical simulation of anchor mooring of the ship under typical working conditions is carried out, and the tension of the anchor chain is checked and the movement is carried out. The response is analyzed.

\section{NUMERICAL MODEL}

\subsection{Bulk carrier finite element model}

The main parameters of the $120.1 \mathrm{~m}$ coastal bulk carrier calculated in this paper are shown in Table 1. In this paper, the ANSYS software is used for modeling. Because the main calculation of the anchor chain tension and the motion response of the ship mooring system under the simultaneous action of wind, wave and flow load, it is only necessary to establish the outer surface model of the ship. Since the ship is symmetrical, it is only necessary to build half of the model and then symmetry. Figure 1 is a grid diagram of the bulk carrier. 
Table 1 Main parameters of $120.1 \mathrm{~m}$ coastal bulk carriers

\begin{tabular}{ll}
\hline Parameter & Numerical value \\
\hline Full length / m & 120.100 \\
Long line length / m & 115.200 \\
Type width / m & 20.200 \\
Type depth / m & 8.600 \\
Design draught / m & 7.770 \\
Design speed / km / h & 14.800 \\
Ship characteristics & Tunnel type \\
\hline
\end{tabular}

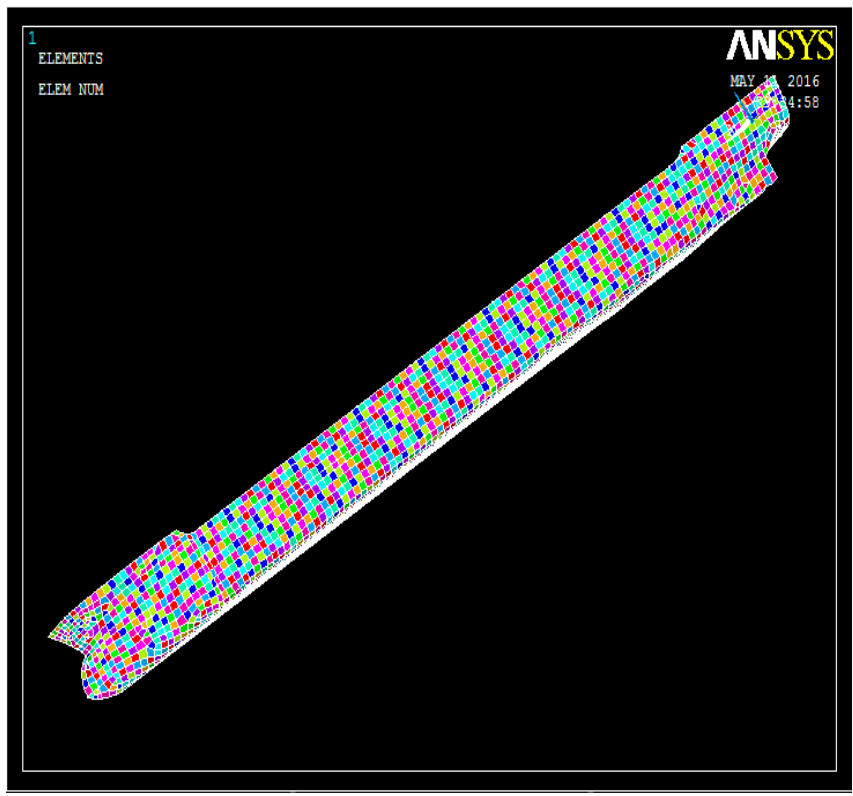

Figure 1. Mesh division of a $120.1 \mathrm{~m}$ coastal bulk carrier

2.2 Establishment of finite element model of mooring system According to the ship's main scale and related regulations, the anchor chain with a chain diameter of $56 \mathrm{~mm}$ was finally selected. The main parameters of the anchor chain are shown in Table 2.

Table 2 Main parameters of anchor chain

\begin{tabular}{lllllc}
\hline $\begin{array}{l}\text { Cable } \\
\text { component }\end{array}$ & $\begin{array}{l}\text { length } \\
(\mathrm{m})\end{array}$ & $\begin{array}{l}\text { chain } \\
\text { diameter } \\
(\mathrm{mm})\end{array}$ & $\begin{array}{l}\text { Wet } \\
\text { weight } \\
(\mathrm{kg} / \mathrm{m})\end{array}$ & $\begin{array}{l}\text { tensile } \\
\text { load } \\
(\mathrm{kN})\end{array}$ & $\begin{array}{l}\text { breakin } \\
\mathrm{g} \text { load } \\
(\mathrm{kN})\end{array}$ \\
\hline $\begin{array}{l}\text { Anchor } \\
\text { chain }\end{array}$ & 375 & 56 & 68.68 & 1710 & 2430 \\
\hline
\end{tabular}

Before establishing the finite element model of the mooring system, the work that needs to be done is to estimate the position of the cable guide hole and the position of the seabed mooring point. The position of the cable guide and the position of the seabed mooring point can be easily estimated based on the ship's profile and the selected chain length. After the estimation is completed, you need to write the DAT file, set the position of the guide hole and the position of the seabed mooring point. After completing the position of the guide hole and the position of the seabed mooring point, you need to anchor the cable guide hole and the seabed mooring point. The chains are connected. Finally, just put the modified DAT file into the AQWA software and calculate it. At this point, the entire finite element model has been established, as shown in Figure 2

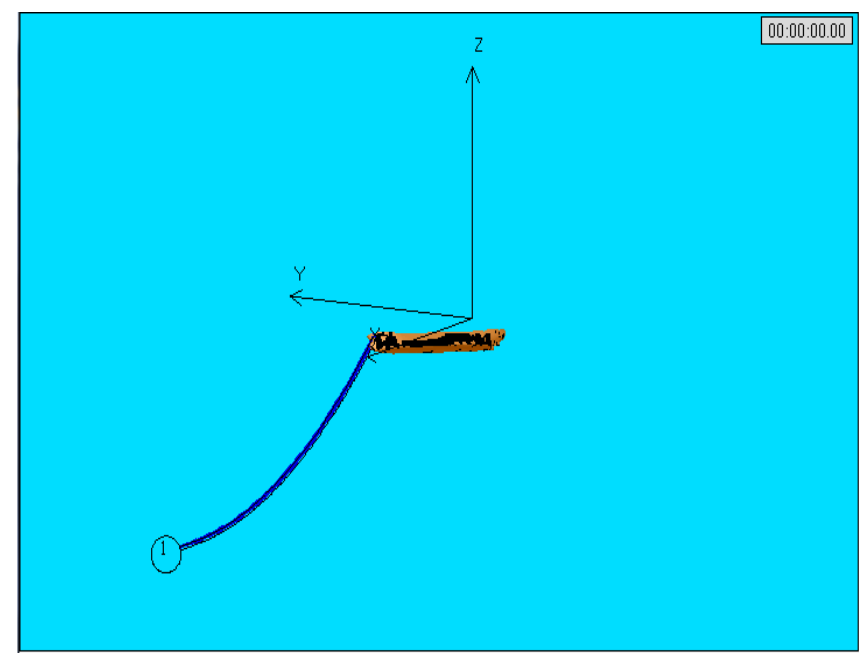

Figure 2 Ship finite element model

\section{CALCULATION AND ANALYSIS OF MOORING SYSTEM}

\subsection{Environmental load}

In order to clarify the movement of the ship mooring system with wind, waves and flow loads, three working conditions were selected, one for each of five years, one for ten years and one for twenty years. In this paper, the water depth is set to $100 \mathrm{~m}$, and the wave direction, wind direction and flow direction are both set to $-180^{\circ}$.

Table 3 Working condition 1

\begin{tabular}{lllll}
\hline $\begin{array}{l}\text { Characteristic } \\
\text { wave height } \\
(\mathrm{m})\end{array}$ & $\begin{array}{l}\text { averag } \\
\text { e } \\
\text { period } \\
(\mathrm{s})\end{array}$ & $\begin{array}{c}\text { current } \\
\text { velocity } \\
(\mathrm{m} / \mathrm{s})\end{array}$ & $\begin{array}{c}\text { wind speed } \\
(\mathrm{m} / \mathrm{s})\end{array}$ & $\begin{array}{l}\text { working } \\
\text { water depth } \\
(\mathrm{m})\end{array}$ \\
\hline 7.4 & 10.7 & 1.221 & 23.6 & 100 \\
\hline
\end{tabular}

Table 4 Working condition 2

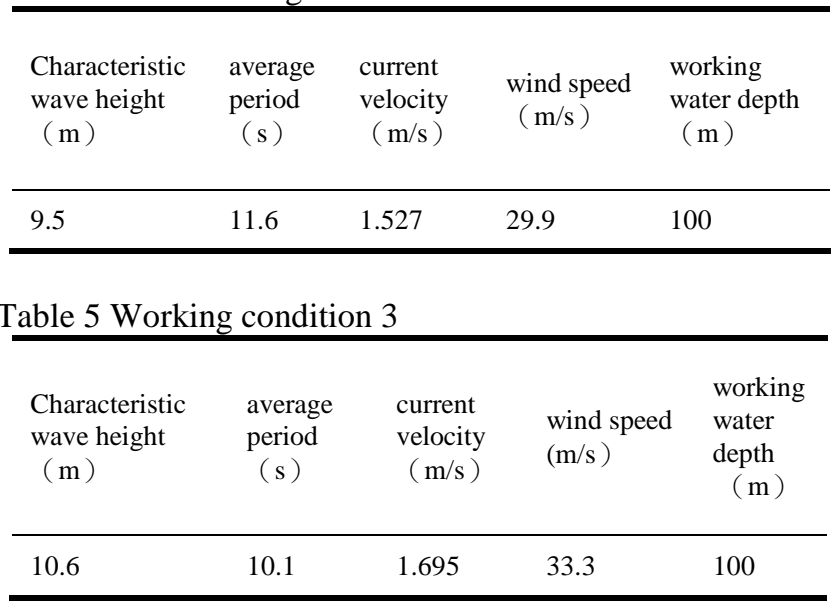

\subsection{Analysis of motion response of ship mooring system}

On the basis of the wind, wave and flow load acting on the ship at the same time, the simulation analysis of the mooring system can obtain the curve of the center of gravity of the ship in the direction of six degrees of freedom with time. Figure 3 to Figure 20 show the time history curves of the motion response of the mooring system under working conditions 1,2 and 3 
International Journal of Engineering and Applied Sciences (IJEAS) ISSN: 2394-3661, Volume-6, Issue-8, August 2019

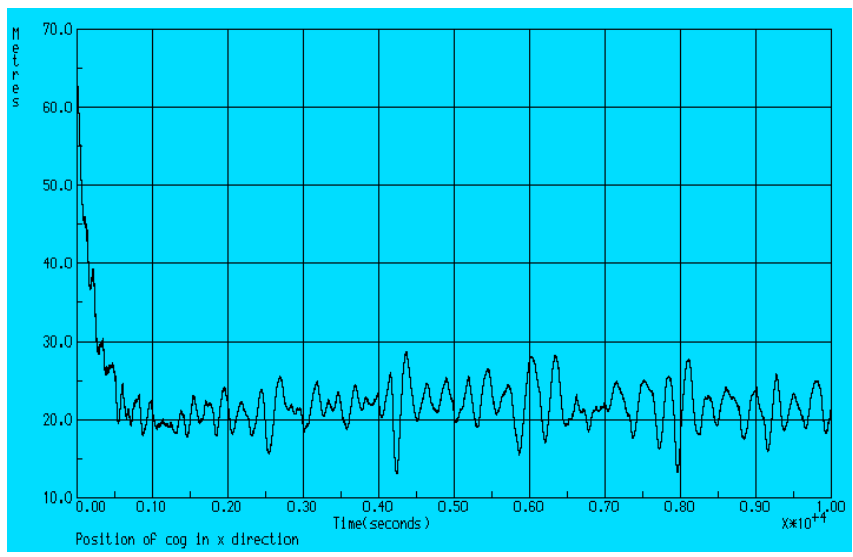

Fig. 3 The ship's Swing time curve under working condition 1

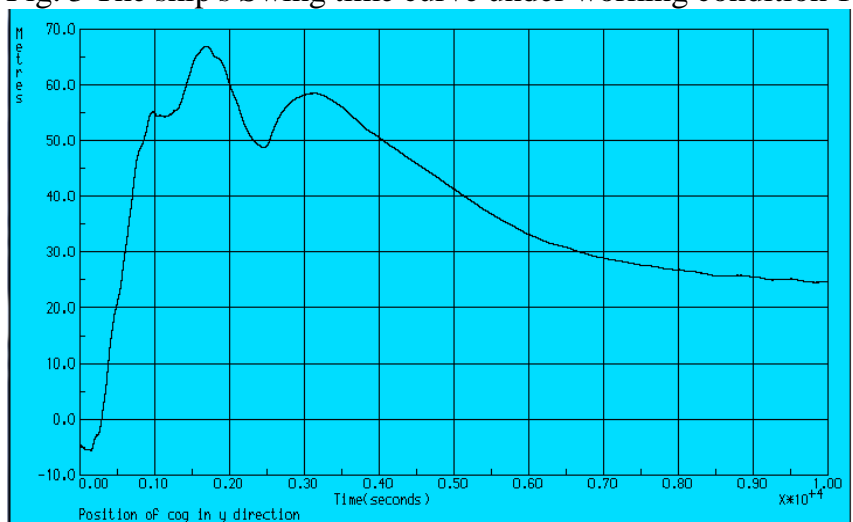

Fig. 4 Ship traversing time curve under working condition 1

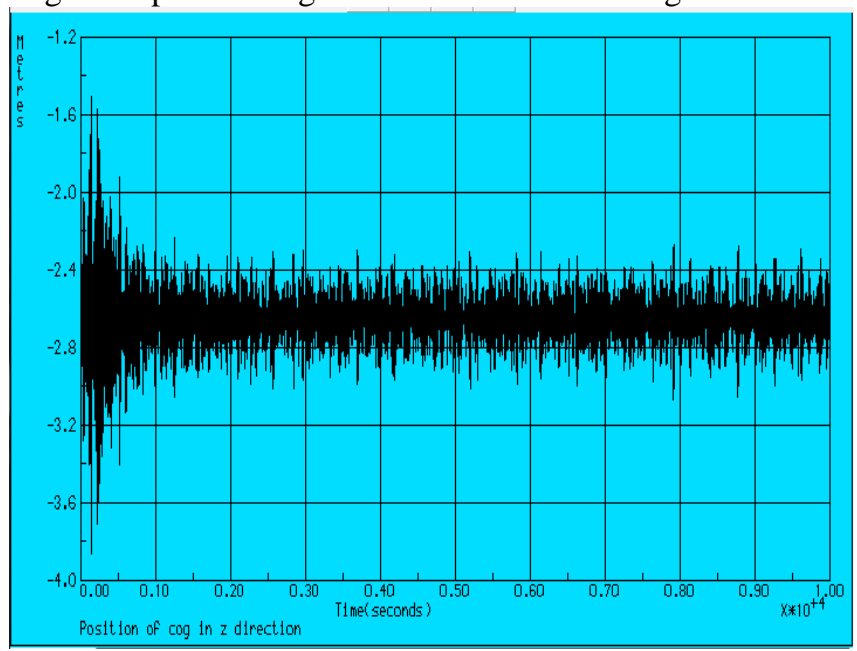

Figure 5 Ship's heave time curve under working condition 1

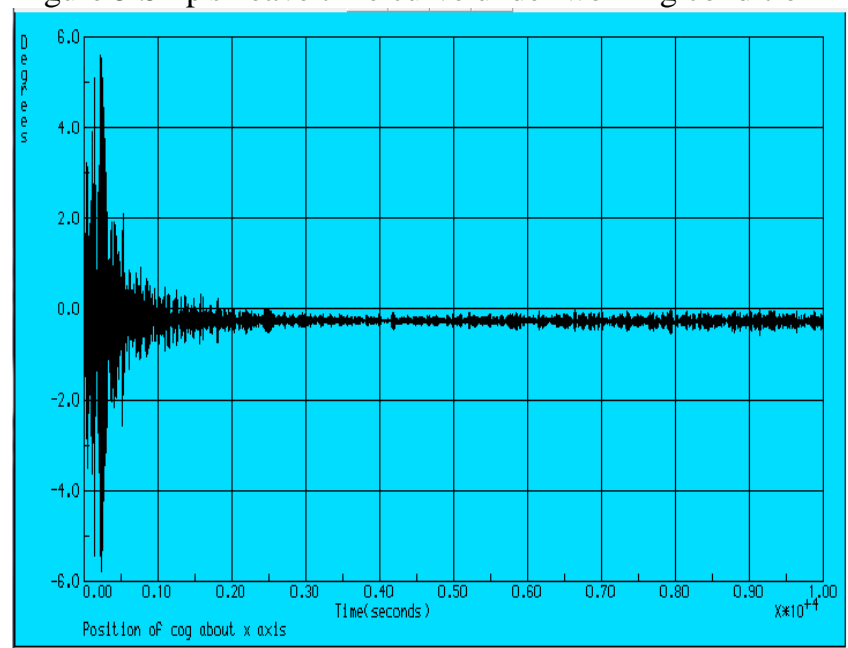

Figure 6 Ship rolling time curve under working condition 1

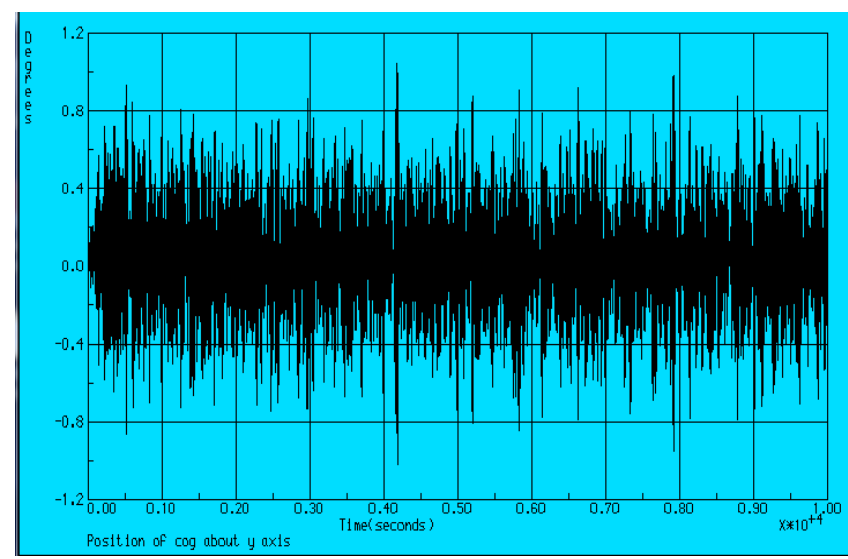

Figure 7 Ship's pitching time curve under working condition 1

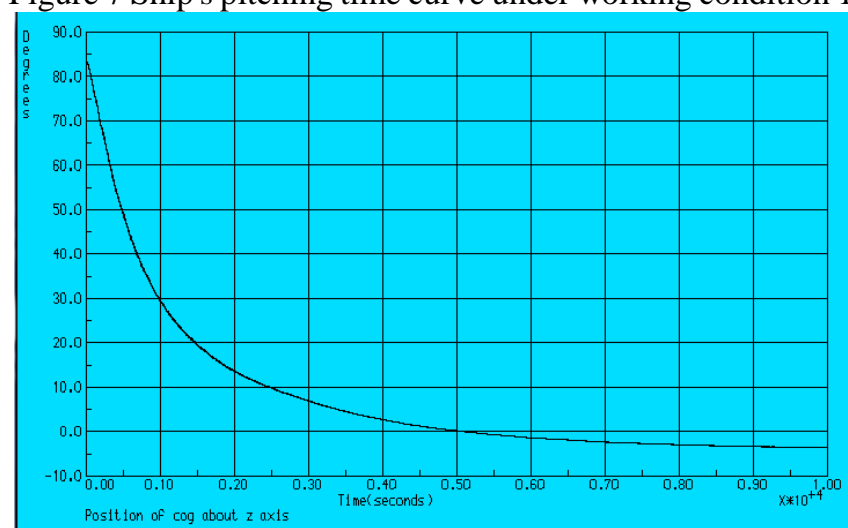

Figure 8 Curve of the ship's shaking time under working condition 1

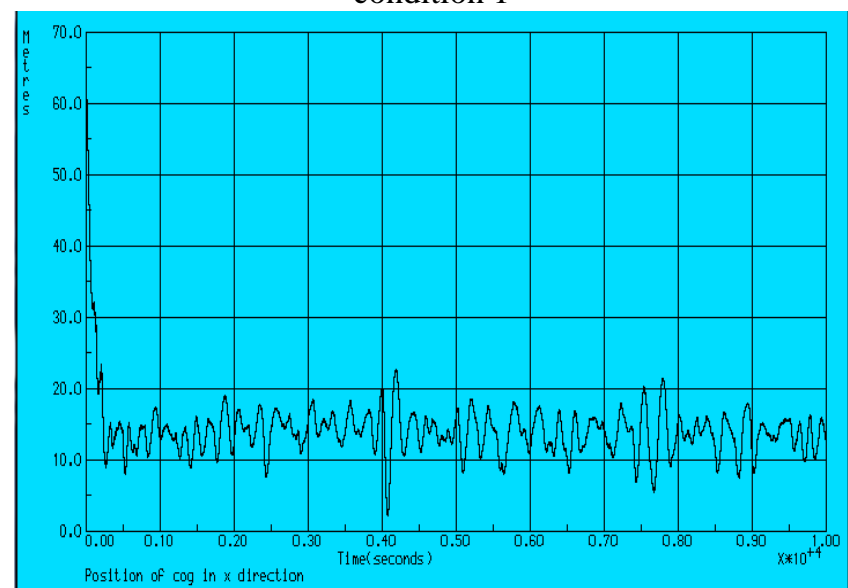

Fig. 9 The ship's Swing time curve under working condition 2

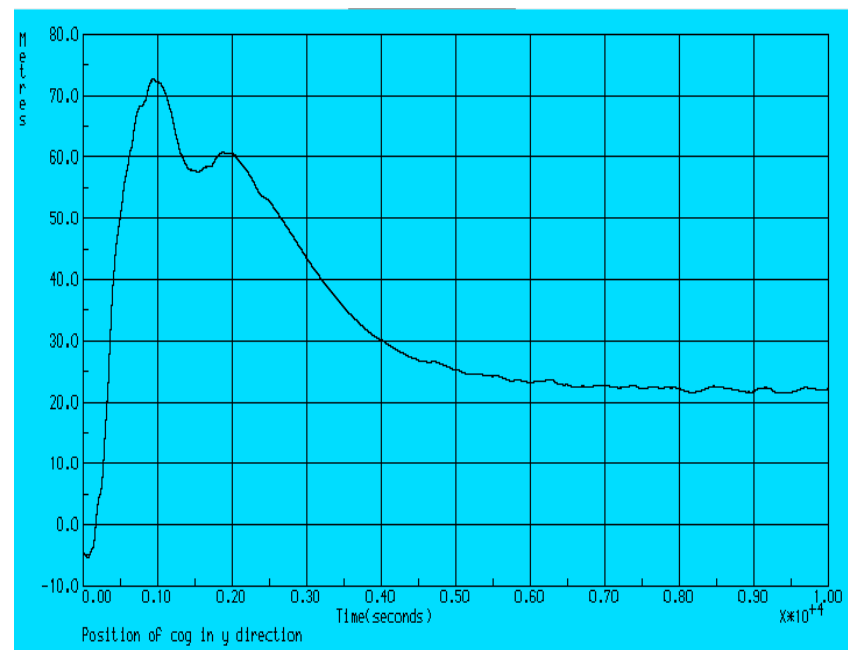

Figure 10 Ship sway time curve under condition 2 


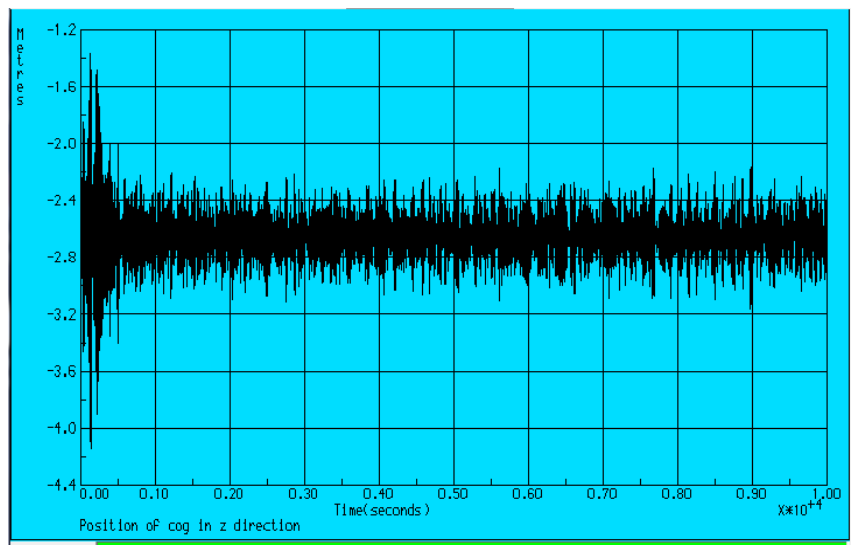

Figure 11 Ship's heave time curve under working condition 2

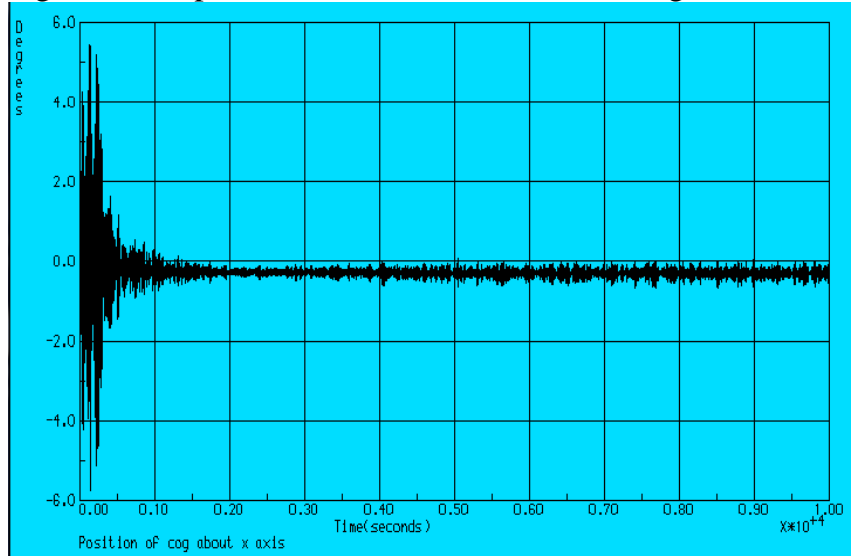

Figure 12 Ship rolling time curve under working condition 2

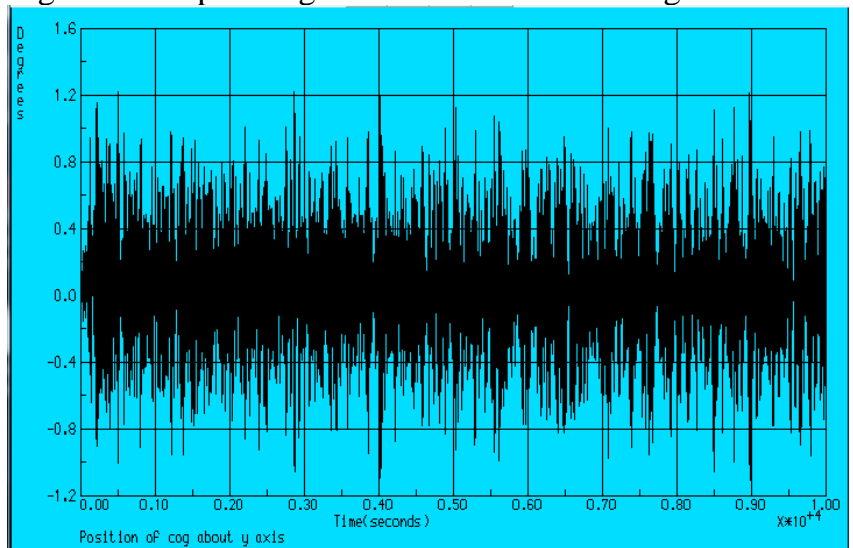

Figure 13 Ship's pitching time curve under working condition 2

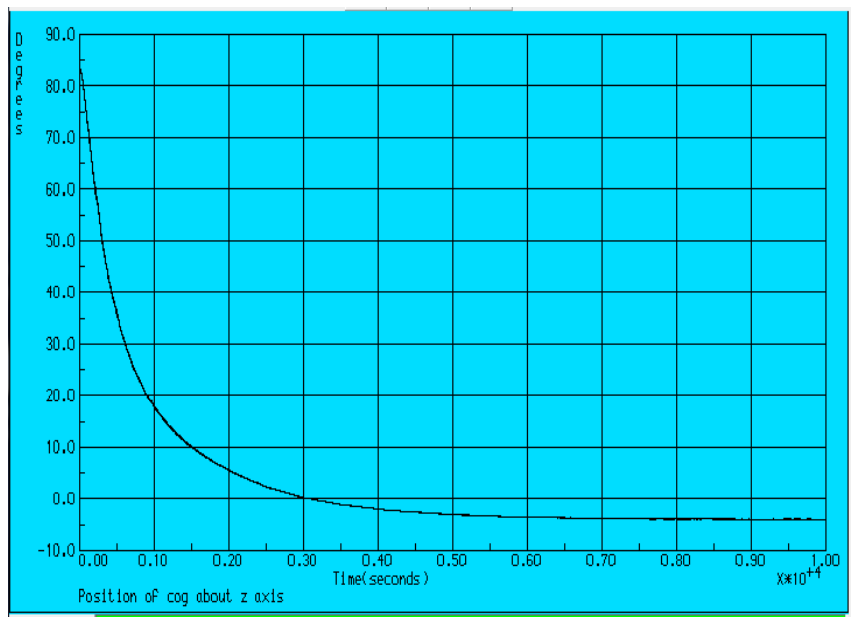

Figure 14 Curve of the ship's shaking time under working condition 2

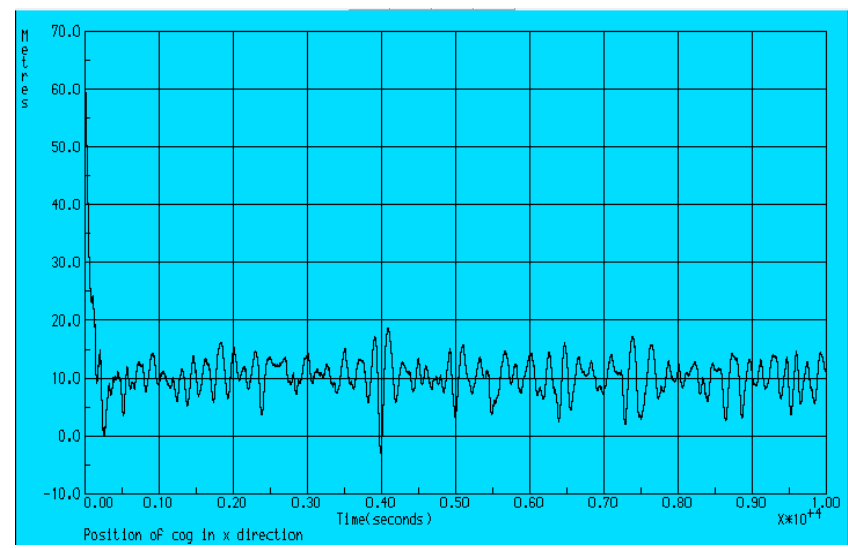

Fig. 15 The ship's swing time curve under condition 3

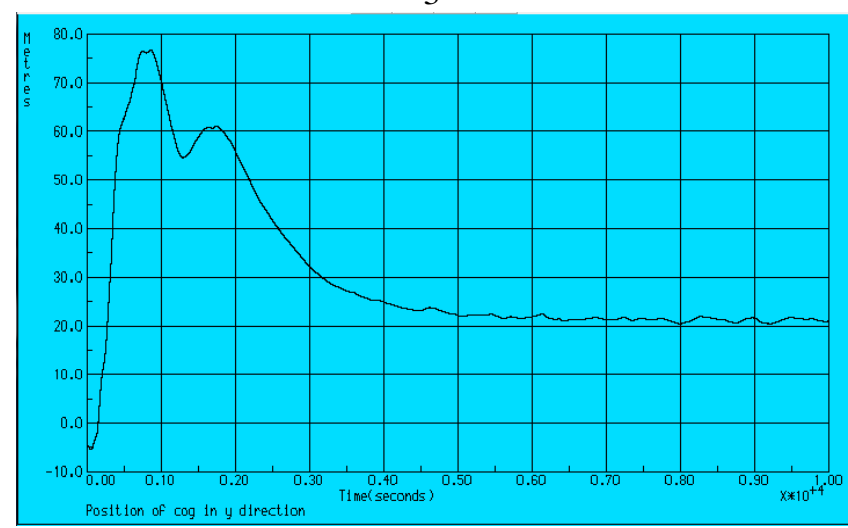

Figure 16 Ship traversing time curve under condition 3

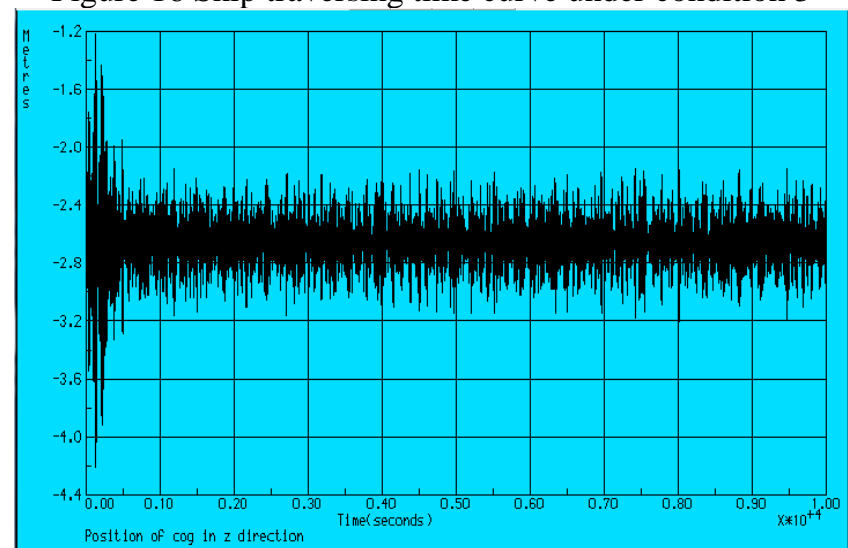

Figure 17 Ship's heave time curve under working condition 3

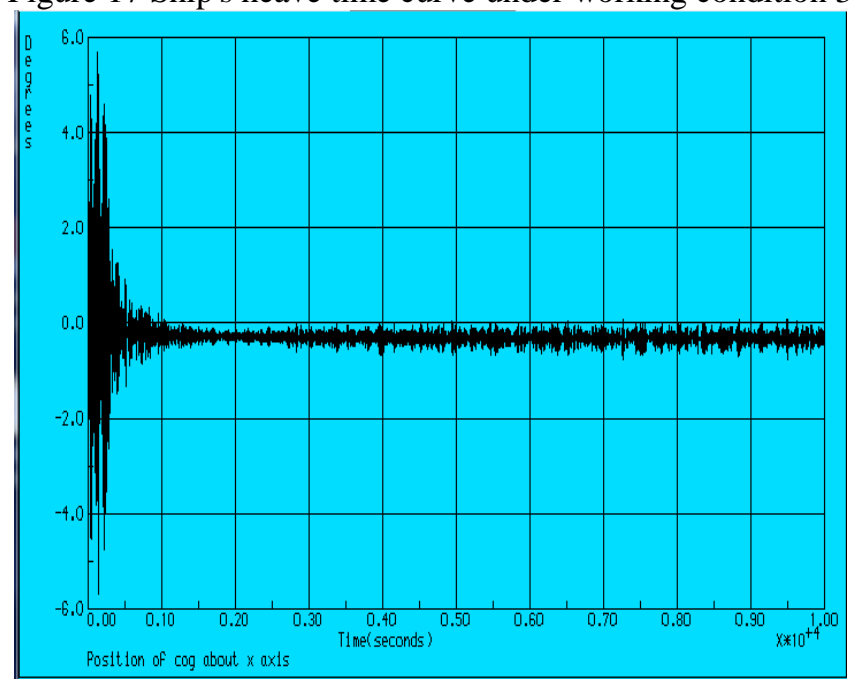

Figure 18 Ship rolling time curve under working condition 3 


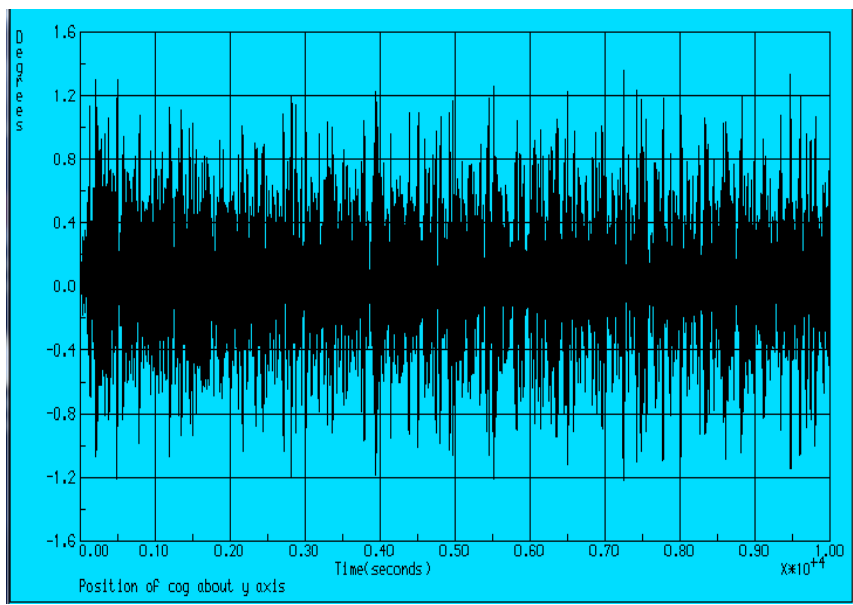

Figure 19 Ship's pitching time curve under working condition 3

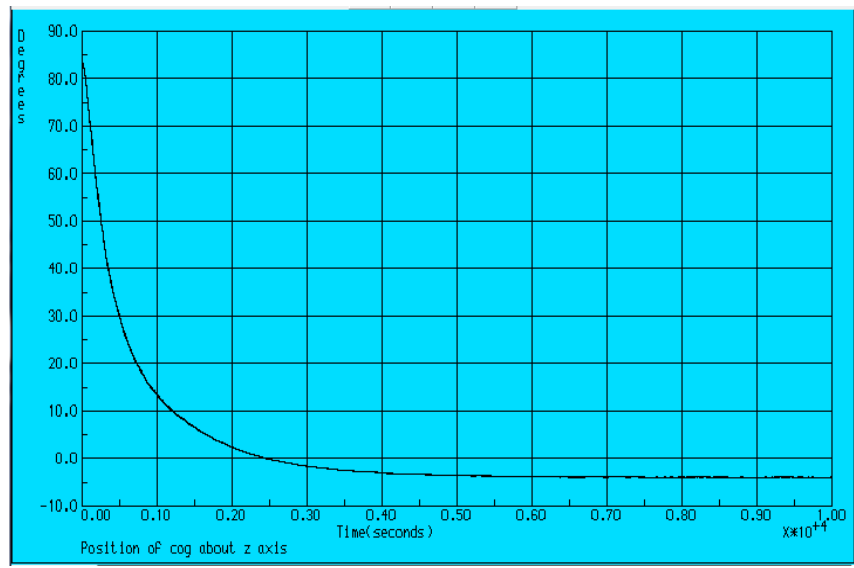

Figure 20 Curve of the ship's shaking time under working condition 3

Since the trend of the central curve of the ship in six degrees of freedom is basically the same under three working conditions, only the value has a size, and the selected condition 3 is representative for detailed explanation.

Under the working condition 3, the ship's turbulent time-history curve has a sharp drop in a very short period of time, and finally oscillates around 10; the ship's swaying calendar curve increases first and then decreases with time. Stabilization is achieved; the ship's heave time curve violently oscillates in a very short time after the start, the amplitude is large, and then the amplitude is reduced, but it is always balanced; the ship's roll-travel curve is similar to the ship's heave time curve. It also violently oscillates in a very short time after the start, the amplitude is large, and then the amplitude is significantly reduced, which is basically 0 ; the ship's pitching time calendar curve has been violently vibrated; the ship's swaying calendar curve is the most gradual, with the The delay of time gradually declines until it stabilizes. Under working condition 3, the ship's center of gravity has changed drastically in six degrees of freedom, but it meets safety requirements.

3.3 Anchor chain tension check of ship mooring system Anchor chain tension check is the most critical task in the design of ship mooring system. The tension of the chain, whether the tension exceeds the breaking load of the chain and the worst sea conditions that the chain can bear are all important to the safety of the ship and the crew. The problem is also the most important part of this paper. Figure 21 to Figure 23 show the time history curves of the anchor chain tension under working conditions 1, 2 and 3

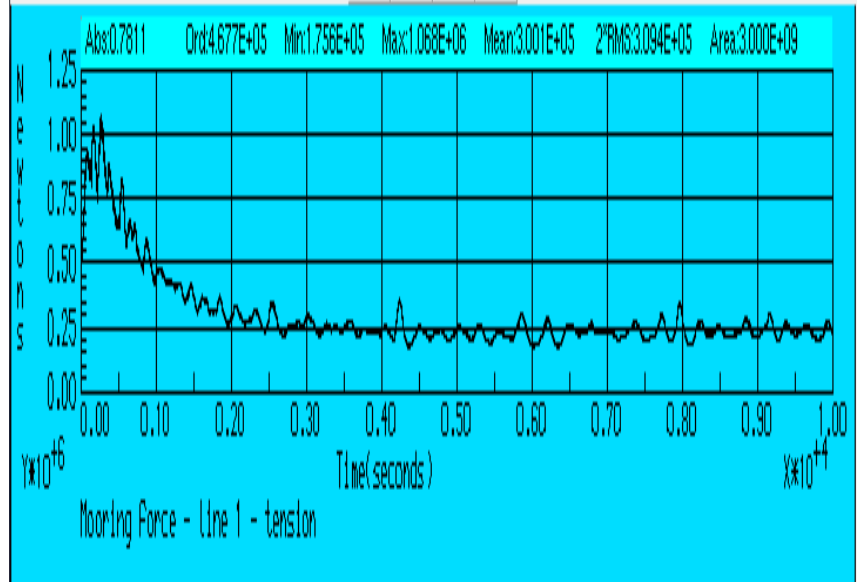

Fig.21 Time curve of ship anchor chain tension under working condition 1

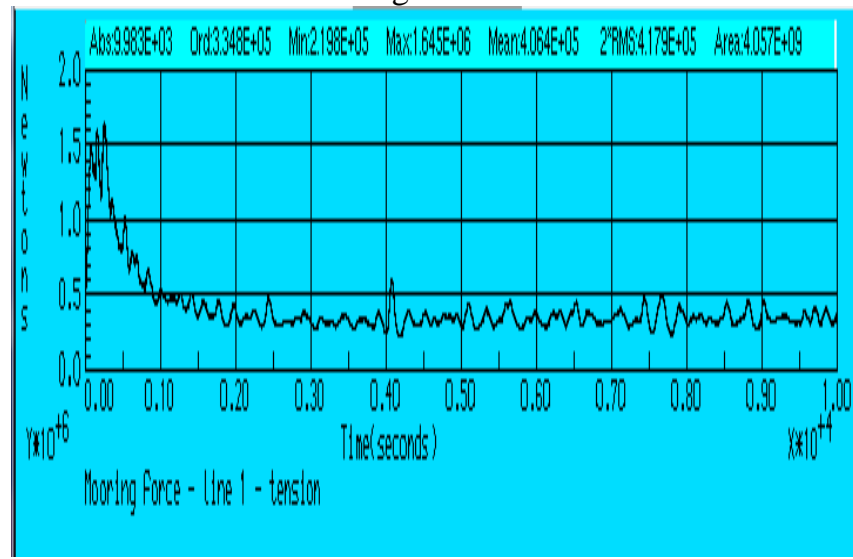

Fig.22 Time curve of ship anchor chain tension under working condition 2

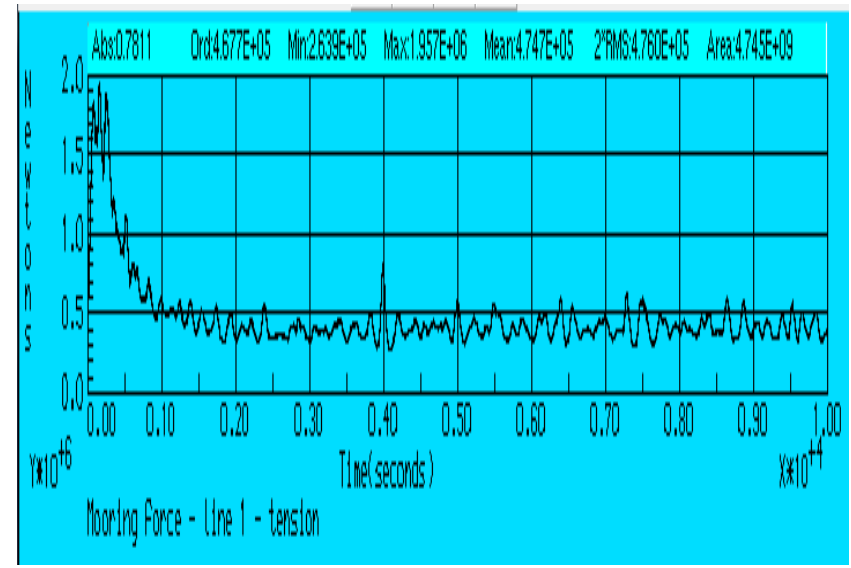

Fig.23 Time curve of ship anchor chain tension under working condition 3

From the tension log diagram of the three anchor chains of the ship, it can be seen that under different working conditions, the tension of the ship's anchor chain is basically the same with time, and the ship's anchor chain will be suddenly received at the beginning of loading time. A large tension, as time passes, the tension of the chain will slowly decrease and eventually reach dynamic equilibrium. The selected anchor chain has a chain diameter of $56 \mathrm{~mm}$ and a breaking load of $2430 \mathrm{KN}$.

Working condition 1 is the sea condition once in five years. It can be seen from Fig. 21 that the maximum tension of the anchor chain is only $1068 \mathrm{KN}$, and the ratio of the breaking load to the maximum tension of the anchor chain is 2.275 , 
which proves that the anchor chain can fully satisfy the ship. Requirements for use in sea conditions once in five years.

Working condition 2 is the sea condition once in ten years. As can be seen from Fig. 22, the maximum tension of the anchor chain is $1645 \mathrm{KN}$, and the ratio of the breaking load to the maximum tension of the chain is 1.477 . It can also be proved that the anchor chain meets the ship at ten. Requirements for use in sea conditions in the first year of the year.

Working condition 3 is the sea condition once in twenty years. As can be seen from Fig. 23, the maximum tension of the anchor chain is $1957 \mathrm{KN}$, and the ratio of the breaking load to the maximum tension of the chain is 1.242 , although the maximum tension of the chain is still less than the anchor. The broken load of the chain, but the margin is less, and it is prone to accidents. Since the selected ship is a coastal bulk carrier, the actual sea conditions encountered are relatively small compared to the checked sea conditions, so the requirements for use are also met.

In order to check the tension of the anchor chain, this chapter uses the AQWA finite element software to set the working conditions of the ship. The selected working conditions are three typical conditions of five years, ten years and twenty years, and finally The variation of the ship's center of gravity with time and the tension of the chain with time are obtained in six degrees of freedom. In the six degrees of freedom, the ship's center of gravity is within the allowable range, and the tension of the chain is also less than the breaking load of the chain and there is a surplus. In addition, the ship is a coastal bulk carrier, and the actual coastal sea conditions are deeper. It is more moderate, so the selected anchor chain meets safety and production requirements.

\section{CONCLUSION}

Based on the $120.1 \mathrm{~m}$ coastal bulk carrier, the finite element model of the ship and its mooring system is established in ANSYS-AQWA. The finite element model is used to analyze the motion response of the mooring system and the tension check of the anchor chain. By analyzing and checking the three typical conditions of the ship, the following conclusions can be drawn from numerical simulation:

It can be seen from the tension check part of the anchoring system of the ship mooring system that the tension of the anchor chain is the same under any working condition: in a very short time, the tension of the chain starts to rise sharply with a larger value. After reaching the maximum value, it begins to decline again until it tends to be dynamically balanced. The maximum tension of the anchor chain under these three working conditions is lower than the breaking load of the anchor chain and there is a surplus, which can meet the corresponding safety requirements. The results of this time value simulation can provide reference and reference for the mooring system of the same type of ship.

\section{REFERENCE}

[1] PI Johansson, A finite element model for dynamic analysis of mooring cables, Mooring Cables, 1976

[2] Gobat Jason I, Grosenbaugh Mark A. A Simply Model of Heavy Induced Dynamic Tension in Catenary Mooring[J]. Applied Ocean Research, 2001, 23: 159-174.

[3] A. P. Shashikala, R. Sundaravadivelu and C.Gnanpathy. Dynamics of A Moored Barge Under Regular and Random Waves. Ocean Engineering. 1997, 24: 401-430.
[4] Bingham. H. B. A Hybrid Boussinesq-panel Method for Rredicting the Motion of A Moored Ship. Coastal Engineering. 2000. 40: 21-38.

[5] Inoue Y, Islam M R. Comparative Study of Numerical Simulation and the Experimental Results for A Parallely Connected FPSO and LNG in Waves. In: Proceedings of the 9th ISOPE Conference. 1999. 360-367.

[6] Inoue Y, Islam M R. Numerical Investigation of Slowly Varying Drift Forces of Multiple Floating Bodies in Short Crested Irregular Waves. In: Proceedings of the 11th ISOPE Conference. 2000. 174-182.

[7] Inoue Y, Islam M R. Effect of Viscous Roll Damping on Drift Forces of Multi-body Floating System in Waves. In: Proceeding of the 11th ISOPE Conference. 2001. 279-285.

[8] Ohkush M. Ship Motions in Vicinity of A Structure. In: Proc. of int'l conf. on Behavior of Offshore Structure, NIT, 1974. 284-306.

[9] Kordan. N. The Motions of Adjacent Floating Structures in Oblique Waves. In: Proceedings of the Third Offshore Mechanics and Arctic Engineering. New Orleans. 1984. 206-213.

[10] Choi Y R. , Hong S Y. An Analysis of Hydrodynamic Interaction of Floating Multi-body Using Higher-order Boundary Element Method. In: Proceedings of the 12th ISOPE Conference. 2002. 303-308.

[11] Fan Ju, Chen Xiaohong, Huang Xianglu. On the contribution of the mooring system to the damping of the slow oscillation of moored floating structure [A].Proceedings of the 1998 International OTRC Symposium [C]. Houston, 1998. 147 154 .

Shenghui Tao, School of Naval Architecture and Ocean Engineering, Jiangsu University of Science and Technology, Zhenjiang 212003, China.

Hui Liu, School of Naval Architecture and Ocean Engineering, Jiangsu University of Science and Technology, Zhenjiang 212003, China 